\title{
Antimicrobial resistance: preventive approaches to the rescue? Professional expertise and business model of French "industrial" veterinarians
}

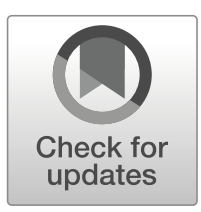

\author{
Nicolas Fortané ${ }^{1,2}$ (D)
}

Received: 19 September 2018 / Accepted: 3 December 2019 / Published online: 6 January 2020

(C) INRA and Springer-Verlag France SAS, part of Springer Nature 2020

\begin{abstract}
This article focuses on the development of veterinary medicine in the industrial pig and poultry production sector. In the current context of controversies over the public problem of antimicrobial resistance (AMR), the veterinary profession is tending to promote a model of preventive medicine that is supposed to reduce the use of antibiotics in livestock farming. However, veterinarians specializing in pig and poultry production ("industrial vets") have in fact been adopting such approaches to animal health for several decades. Based on 28 interviews with pig and poultry veterinarians practicing or having practiced in western France between the 1970s and the 2010s, the article aims to understand how such a form of professional expertise has developed, and the business model that underpins it. Contrary to public discourses which promote preventive approaches as a way to diversify professional expertise and to disconnect veterinary incomes from drug sales, it is indeed this economic model that has allowed the development of such approaches within industrial livestock farming. Modern strategies for reducing antibiotic use should therefore seek less to renew the professional expertise of veterinarians than to find new ways to valorize it economically.
\end{abstract}

Keywords Veterinary profession - Antimicrobial resistance - Veterinary drug market . Intensive livestock farming $\cdot$ Animal health $\cdot$ Professional expertise $\cdot$ Prevention $\cdot$ Pig and poultry production

Nicolas Fortané

nicolas.fortane@inra.fr

1 Institut National de la Recherche Agronomique, IRISSO (CNRS, INRA, Paris-Dauphine, PSL Research University), Paris, France

2 Department of Global Health and Development, Faculty of Public Health and Policy, London School of Hygiene and Tropical Medicine, London, UK 
The French veterinary profession is currently undergoing major changes; or at least it tends to see itself as being at the heart of a period of major challenges that are pushing it to reinvent itself. This is not the first time that it has had to face such a reflexivity test, even in recent history (in the British case, some historians even see a cycle-Woods 2011a), but recent literature produced by professional veterinary organizations shows the importance of what is currently perceived as a need for self-analysis and change (ONDPV 2018; VetFuturs France 2018). There are several issues that might explain why this period is favourable to such a prospective assessment of veterinary futures. One of the most important concerns the controversies and public policies that have developed over recent years with regard to the issue of antimicrobial resistance (AMR), which has directly challenged the economic and professional model of farm animal veterinary practices that were setting drugs (mostly antibiotics) up as a cornerstone of veterinary activity, as a source of both income and professional expertise.

Cross-fertilization of research on the veterinary profession and drug regulation is not common. Although veterinarians have aroused the interest of certain historians and sociologists of professions, this has essentially been in relation to the analysis of this social group's process of professionalization (Berdah 2012; Mitsuba 2017), its role in animal health or food safety policies (Woods 2011b; Enticott et al. 2011; Bonnaud and Fortané 2016, 2018), the dynamics that contribute to its specialization (Gardiner 2014) or feminization (Surdez 2009), or finally to knowledge and professional practices in farm (Shortall et al. 2016; Ruston et al. 2016) and small animal medicine (Sanders 1994; Morris 2012). As for the regulation of veterinary drugs, there are also several studies by historians on the vaccination of animals against major zoonoses or epizootic diseases (Woods 2004; Berdah 2018), sometimes on the veterinary pharmaceutical industry (Corley and Godley 2011), and more recently on the AMR issue (Kirchhelle 2018). Yet unlike the uses of human medicines that medical anthropology has been able to theorize and document for many years (Whyte et al. 2002), the uses of veterinary medicines, i.e. the conditions under which they are prescribed, dispensed and used, are rarely studied, except in interdisciplinary literature from the field of veterinary sciences (Speksnijder et al. 2015; Coyne et al. 2016).

This article tries to open a way to cross-fertilize these reflections. Using recent debates on the AMR problem, it proposes to examine the relationship between the development of professional veterinary expertise and of the drug market, based on the case of a specific segment of the profession, namely veterinarians specializing in industrial poultry and pig production in western France. It thus puts the AMR issue under a broader lens as it analyses ongoing changes within the veterinary profession not as potential consequence of recent measures aiming to reduce antibiotic use, but rather as a reason for the way the problem is now framed. Indeed, it is common to hear professional organizations or public authorities state that in order to reduce their economic dependence on antibiotic sales, vets must rethink their activity by favouring preventive approaches to animal health which would involve a diversified range of services and would contribute to placing vets in an advisory role with a holistic vision of livestock farming or even of the food supply chain (VetFuturs France 2018). However, such a form of professional expertise, combined with a particular business model for the practices promoting it, is not 
fundamentally new. If it is at the heart of contemporary debates, it is because it is based and supported by far earlier dynamics that initially had nothing to do with AMR, but which used the opportunity of current controversies surrounding antibiotic use, sale and prescription to reinforce and legitimize a certain vision of veterinary medicine, based on preventive approaches to animal health.

Poultry and pig medicine in industrial production is an especially interesting area for an analysis of these dynamics. Firstly, because approaches to animal health that have developed in this field are very singular and characteristic of the intensive farming methods used in these sectors, particularly in the Brittany and Pays de Loire regions where a large proportion of the production is located. Indeed, a certain vision of preventive medicine was developed by pig and poultry vets in the 1970s and 1980s, even if the issue of this form of veterinary expertise has not always been raised in these terms. This article therefore aims to understand the professional knowledge, practices and economic model upon which this kind of expertise is based, and why the current AMR context is an opportunity to expand it (or at least attempt to). Secondly, pig and poultry vets make up an extremely small and autonomous segment of the profession (which makes it possible to draw up a fairly representative picture) although its homogeneity should not be overestimated. This article thus seeks to provide a thorough analysis of this very particular part of the veterinary profession, the specificities of which have almost never been addressed by the literature. Despite their small numbers, "industrial" vets are nevertheless an essential component of the profession, because they manage the health of an economic sector which supplies a considerable share of national animal production.

It is not easy to estimate the number of veterinarians specialized in poultry and pig production. The professional directory (known as the "Roy directory") does not specify the specializations of the registered vets and professional demographic surveys do not provide these data (ONDPV, 2018). One can nevertheless trust the estimations of veterinary practitioners themselves, which generally consider that in France there are between 200 and 300 pig vets and between 100 and 200 poultry vets. Out of a total population of approximately 18,000 veterinarians, including 7,000 "rural" or mixed vets, this represents just a tiny part of the profession (at least in strictly quantitative terms; we are not talking here about their degree of power or influence within the profession).

In French, veterinarians specializing in pig and poultry production are usually called "indus' vets" (for industrial veterinarians), which refers to the farming system in which they operate. This expression is in opposition to "rural veterinarian", which is the official equivalent of the English term "farm animal veterinarian" but which in fact needs to be understood in the sense that it is used by practitioners: "rural" vets are (dairy or beef) cattle vets as opposed to "industrial" vets who specialize in pig, poultry and sometimes rabbit medicine (although when they have to define themselves publicly they usually prefer to use the term "vet in organized production" which is less negatively connoted than "industrial vet").

Despite this small workforce, this professional segment is not particularly homogeneous. We can observe certain variations in their practices or knowledge that relate to various elements:

- Status: self-employed vets (from independent or franchised practices) or former "co-operative" vets ${ }^{1}$

- Number of clients: generally between 100 and 200

- Geographical coverage: variable size depending on the density of farming in the work area, which has an impact on veterinarian availability (and therefore on relationships with clients and competition with other vets or technical advisors)

- Subspecies specialization: especially in poultry farming where veterinarians can specialize in broilers, laying hens, wild birds, turkeys, ducks...

- Type of farming and industry: while the majority of poultry and pig vets work with "production" farms, some specialize in breeding farms or hatcheries.
} 

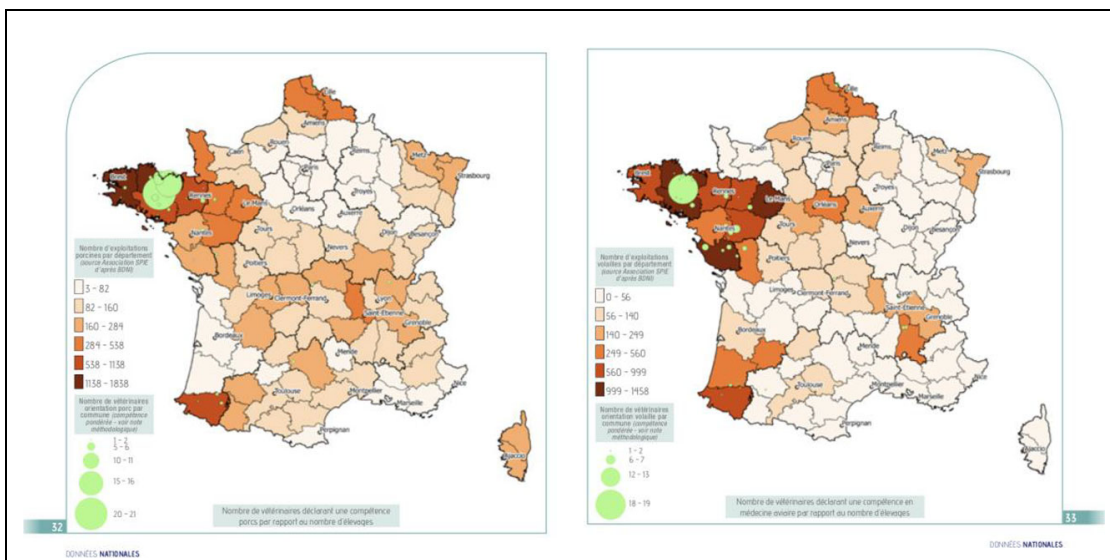

Geographical distribution of pig (left) and poultry (right) farms and veterinarians (ONDPV, 2018).

\section{Methods and sampling}

The study is based on 22 semi-structured interviews (12 with pig vets and 10 with poultry vets) conducted in 2014 and 2015 in Brittany and Pays de Loire, as part of a research project on antibiotic use in livestock. The article also draws on preliminary data from a study begun in 2018 on the establishment of the first veterinary practices specializing in poultry and pig production in the 1970s and 1980s ( 6 semi-structured interviews so far: 3 with retired pig vets and 3 with retired poultry vets).

The 22 interviewees of the first study were contacted through professional organizations which agreed to provide us with a list of veterinary practitioners based in Brittany and Pays de Loire. Very few refused the interviews and when they did so, it was due to a lack of time. With the exception of two retired pig vets, they were all aged between 30 and 50, which is largely representative of the population of farm animal vets (average age: 43 - ONDPV, 2018). Only 5 were female ( 2 poultry vets and 3 pig vets), which is below average as women represent approximately $35 \%$ of farm animal vets (ONDPV, 2018) ${ }^{2}$. For the second study we identified one veterinarian from a book he published ${ }^{3}$, and used snowball methodology to identify and recruit the other participants. They are all men between 60 and 90 years old.

The interviews lasted between 90 minutes and 3 hours. They were all performed face to face, recorded and transcribed. A thematic analysis was performed.

The article opens with a brief presentation of the political context and controversies surrounding the AMR problem, and how the French veterinary profession has faced up to this by defending the preventive medicine model. It then describes this form of expertise in the professional segment studied here, showing why pig and poultry vets chose this specialization. The article then looks at the origins of these preventive approaches to animal health, both in terms of knowledge and practices, and the economic model associated with it. Finally, it reviews the strategies currently developed by industrial vets to adapt to the constraints of increased control of antibiotic use in livestock.

\section{The AMR problem and the preventive "solution"}

The problem of antibiotic use in livestock farming is not new. As soon as these molecules were introduced in agriculture in the late 1940s, there was controversy 
concerning the development of resistant bacteria in animals and food, and the risks of human contamination (Bud 2007). Yet for several decades, this issue has been eclipsed by the belief in a permanent renewal of the therapeutic arsenal, consisting in thinking that the continuous discovery of new antibiotics would compensate for the development of increasingly resistant bacteria (Podolsky 2018). After the Swann report in 1969, a series of measures to control the use of antibiotics as growth promoters ${ }^{1}$ was nevertheless adopted in Europe, progressively separating the molecules used in agriculture and human medicine (Kirchhelle 2018). But 20 years later, during the avoparcin crisis $^{2,3,4,5}$ these measures were considered ineffective (in the sense that they did not prevent the transmission of resistant bacteria between humans and animals) and the use of antibiotics as growth promoters was finally banned in the European Union in $2003^{6}$ (Kahn 2016).

The problem of antibiotic use in livestock farming as we know it today reemerged in the late 2000 s, this time focusing on veterinary uses, i.e. on curative or preventive uses with veterinary prescription (Fortané 2019). Veterinarians were directly accused of being responsible for the overuse and misuse of antibiotics (and therefore for the spread of resistant bacteria) on the basis of a fairly simple argument: their supposed professional "conflict of interest". Indeed, in France, since the 1975 Act on veterinary pharmaceuticals, vets have had a dual monopoly on the prescription and supply of medicines (Hubscher 1999). Even if, in theory, delivery is shared between three beneficiaries (veterinarians, pharmacists and approved co-operatives), vets capture the vast majority of the curative drug market (of which antibiotics constitute the main category) (Guillemot and Vandaële 2009). The argument that veterinarians over-prescribe antibiotics in order to increase their incomes then became the main framing of the AMR problem.

This construction of the problem was in reality carried by a coalition of human health actors (doctors, pharmacists, health administration) whose political agenda was twofold. On the one hand, they defended a measure that crystallized the debates around the years 2009-2013: the "decoupling" of prescription and delivery, which consists in applying the professional and economic model that prevails on the human drug market, i.e. reserving prescriptions to physicians and sales to pharmacists. Decoupling basically means forbidding veterinarians from selling pharmaceuticals, as is the case in countries such as Sweden or Spain (Fortané 2016). On the other hand, this coalition supported the concept of "critically

\footnotetext{
${ }^{1}$ This status no longer officially exists as since 2007 all veterinary companies must be registered as independent practices (State Council Judgment $n^{\circ} 285652$ of January 24th, 2007, known as the Riaucourt Judgement). Working methods and contractual relations (exclusive contracts in particular) nevertheless continue to differentiate between the functioning of independent practices and that of former "cooperative" vets.

${ }^{2}$ These data nevertheless concern all farm animal vets (whatever the species in which they are specialized) and there are no specific data on pig and poultry vets.

${ }^{3}$ In order to preserve the anonymity of the participants, we are not citing this book.

${ }^{4}$ Growth promotion is a way of using antibiotics which is neither curative nor preventive, and which is designed to enhance the growth of farm animals (and therefore the productivity of the farm) by supplementing their food with sub-therapeutic doses of antibiotics. This type of antibiotic use does not require veterinary prescription.

${ }^{5}$ Avoparcin is an antibiotic that has been used as growth promoter. Danish authorities wished to ban it and therefore advocated for a change in EU regulation.

${ }^{6}$ Regulation 1831/2003/EC on additives for use in animal nutrition.
} 
important antibiotics", the principle of which is to reserve certain molecules, in particular the latest generations of antibiotics, for human medicine. From a political and institutional point of view, this period was extremely interesting because it put the spotlight on definitional and jurisdictional conflicts between different social groups for the control of the legitimate use of antibiotics. It finally ended in a relative victory for veterinarians who succeeded, at the end of an unprecedented mobilization, in reversing the stigma that human health stakeholders assigned to them. Indeed, vets have been able to impose the image of a profession that is not guilty of overusing antibiotics but which is instead accountable for their proper use. The notions of prudent, judicious, rational or responsible use, now widely used in AMR debates, are thus a social construct produced by conflicts between social groups for the definition of the legitimate use of antibiotics (Fortané 2019).

This veterinarian victory led to the withdrawal of the two emblematic measures (decoupling of prescription and delivery; ban on critically important antimicrobials) supported by the coalition of human health actors. In return, a stricter framework for the use of antibiotics in animal husbandry was implemented between 2014 and 2016: margins on the sale of antibiotics are now limited and the retail price of antibiotics must be the same for every client, ${ }^{7}$ and antimicrobial susceptibility tests are mandatory for the prescription of critically important antibiotics. $^{8}$ But once again, the most important part of this victory certainly concerns the changes regarding the image of the profession. Indeed, veterinarians not only reversed the stigma and positioned themselves as guardians of antibiotics, they were also able to re-appropriate the problem by highlighting the way they could solve it. Without denying that the economic model of the profession was too financially dependent on antibiotic sales, and that antibiotic use may have been too prevalent in animal care in the past, vets started to defend the development of preventive approaches which would, according to them, be the only way to ensure the transition towards an economic and professional model guaranteeing responsible use of antibiotics. This view was reinforced and supported by farmers and public authorities who also called for the development of such approaches which are usually promoted by national AMR policies (Fig. 1) in France and in other countries (Badau 2016; Piquerez 2019). ${ }^{9}$

At the heart of this new prospective narrative for the profession and its role in managing the AMR problem, we can observe the construction of a (supposedly) new conception of animal health, which is not based on a strictly clinical approach to diseases but on a holistic vision of animals and livestock farming (biosecurity, hygiene, nutrition, good husbandry practices, etc.). In the posters above, veterinarians are portrayed as the gatekeepers of such an approach, through their transversal role as "health advisors". This professional model, based on the knowledge and practices of preventive approaches to animal health, goes hand

\footnotetext{
${ }^{7}$ Law for food, agriculture and forestry n ${ }^{\circ}$ 2014-1170 of October 13th, 2014.

${ }^{8}$ Decree no. 2016-317 of March 16th, 2016.

${ }^{9}$ When public authorities and the veterinary profession began to conceive this campaign, a third poster was designed, saying: "my vet is much more than a mere drug supplier, he is also a teacher! He prescribes the medicines I need ... but above all he talks to my farmer to make sure that I am perfectly fed, sheltered and vaccinated'. However this poster was not retained for the campaign because of its relatively sensitive headline.
} 


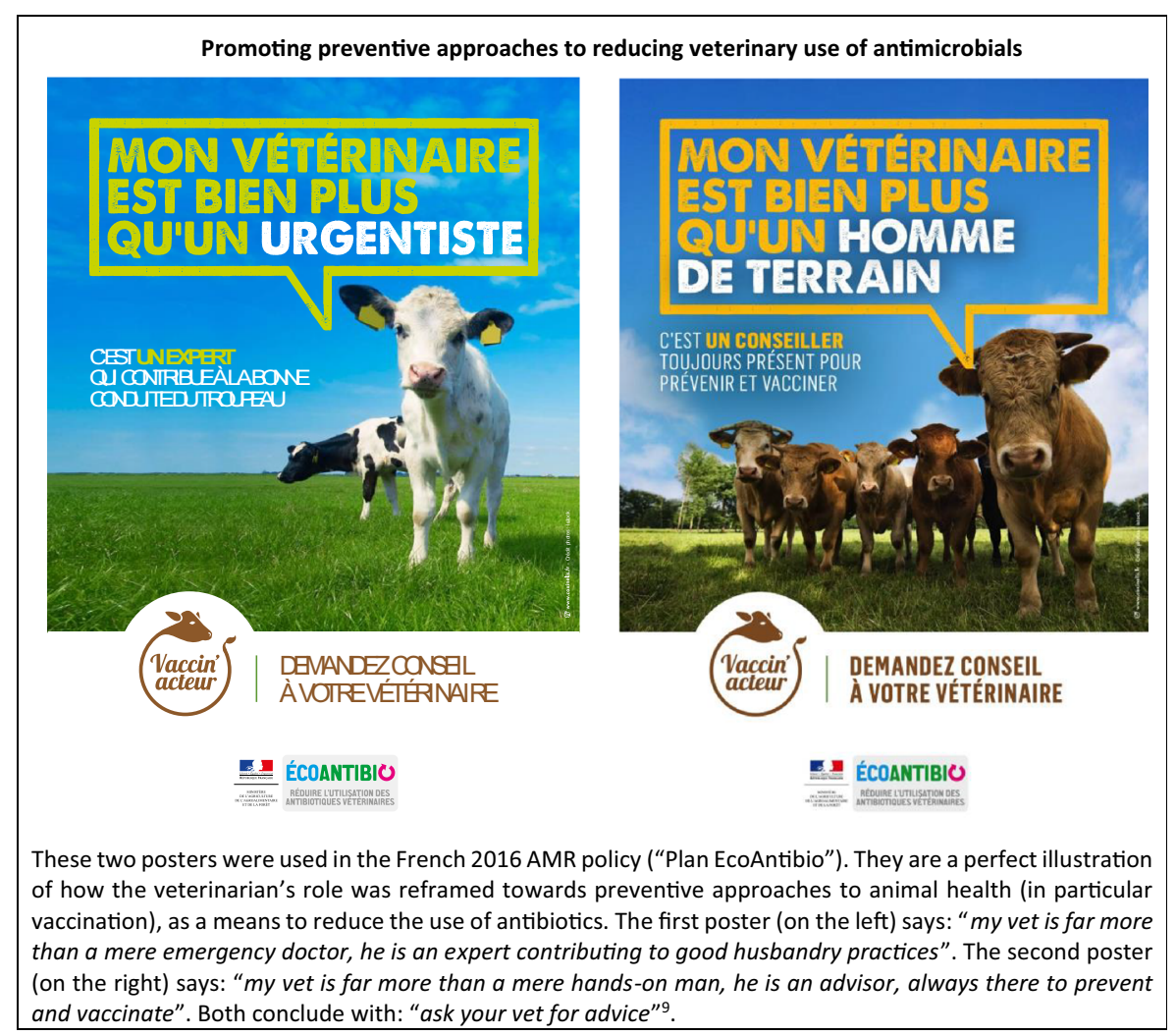

Fig. 1 Promoting preventive approaches to reduce veterinary use of antimicrobials

in hand with an economic model where the incomes of veterinary businesses would be more diversified since these new "health advisors" would be able to monetize a wider range of goods and services (hygiene and nutrition products, bacteriological analyses, livestock audits, etc.) than just pharmaceuticals.

Could we look beyond the symbols and images of professional and political discourses and see whether these preventive approaches that might change the way veterinary medicine is practiced, and how antibiotics are used, rely on actual knowledge and practices and, if so, where and since when? The fact is that this model of preventive veterinary medicine seems in reality to be quite typical of a very particular segment of the veterinary profession, the one this article proposes to describe, namely industrial vets. The remainder of the article thus seeks to address the following two questions: is this form of professional expertise really perceptible in the field, and is its development truly linked to the global context of the AMR problem and to recently implemented policy measures, or does it have other origins and raisons d'etre that might actually

\footnotetext{
${ }^{0}$ When public authorities and the veterinary profession began to conceive this campaign, a third poster was designed, saying: "my vet is much more than a mere drug supplier, he is also a teacher! He prescribes the medicines I need ... but above all he talks to my farmer to make sure that I am perfectly fed, sheltered and vaccinated'. However this poster was not retained for the campaign because of its relatively sensitive headline.
} 
offer new insights into the understanding of the current transformations within the veterinary profession?

\section{Being a vet in industrial and intensive livestock farming}

When poultry or pig vets are asked why they chose this specialty, they often point out a huge contrast between what they do and the way they perceive cattle (i.e. "rural") or companion animal vets. They feel that being an "industrial vet" essentially relates to four characteristics.

Firstly, veterinarians specialized in poultry or pig medicine attach importance to working at the heart of the agri-food system, with livestock farming professionals. Many of them have agricultural family origins and believe that they chose this profession in order to maintain a strong link with the rural world. They perceive farmers as animal experts, unlike pet owners, and see their activity as teamwork alongside skilled professionals, with whom it is easier to interact and who can also provide them with knowledge about animals. Their clients are therefore also their partners in animal health management: they can trust them, rely on them and delegate tasks to them.

Secondly, pig and poultry vets consider their work to be a permanent renewal, as opposed to the repetitive and sometimes boring work of cattle vets who constantly reproduce the same gestures and who are rarely motivated or intellectually stimulated by new situations and new challenges. Most of them, whether they are young vets or already have 15 or 20 years of experience, tend to compare their professional activity with the image of the "emergency vet" (or "fire brigade" vet), available day and night to care for sick animals. From their point of view, this traditional activity is typical of cattle vets, corresponds to the past and relates to a type of work which is limited to clinical diagnosis, drug prescription and/or surgery (e.g. midnight calving). In their opinion, the only objective of such a way of working is to ensure that clients are satisfied with an occasional intervention and that they will once again call upon veterinary services the next time health problems occur. The point here is not to claim that this is what cattle vets are actually doing, ${ }^{10}$ but simply to note that this narrative is widely used to define, by contrast, the professional identity of industrial vets.

I am indirectly from a rural family, that is to say that my grand-parents, my uncles, they all worked as farmers, in mixed farming and mixed animal farming, from both sides of my family. It is just my parents who had access during the postwar period to national education programmes and became teachers or researchers. So I am from the third generation but I spent a lot of time at the farm.

\footnotetext{
${ }^{10}$ Although some of the characteristics that pig and poultry vets tend to associate with cattle vets have actually been observed in other studies, in particular the fact that cattle vets do not have a high opinion of the technical expertise of the farmers they deal with (Shortall et al. 2016). These opinions of their clients nevertheless depend to a certain extent on the type of farm and farmers they relate to: cattle vets have better professional relationships with "commercial farmers" (managers of large, modern and business-oriented farms) as the latter tend "to understand the need to use the vet as a disease prevention consultant rather than to treat individual sick animals: i.e. part of vets' desired move from a 'test and treat' to a 'predict and prevent' model of veterinary intervention" (Shortall et al. 2018, p. 597). In addition, this shows that a tension between "fire brigade" work and advisory veterinary work is also present within a certain section of the cattle vet profession.
} 
I became a vet to take care of farm animals because I like being outside and having an intellectual occupation. So that is the reason why.

$\underline{\text { Poultry vet, } 2015}$

So at vet school, you didn't think about working with dogs?

Certainly not (laughs)! That was my nightmare! When you work in the pig sector, what is good is that you work $100 \%$ on farms. Because when you work with cattle, most of the time you have to do some small animal work as well. And what I want is to work with professionals who are producing the animals we eat.

Pig farmers (well, not all of them but most of them) have very good technical skills. Pigfarming is a very dynamic sector, you never get bored! We often have to upgrade the farms to new standards so it's always evolving. Research also moves very fast, the pharmaceutical industry innovates a lot so it's interesting. (...) And to be honest, what interests me the most is this kind of follow-up, not being a "fire brigade" vet. But I can't talk very knowledgeably about the "classic" rural vet as I never was one. But what I do think about this kind of practice is that there is a lot of emergency and "fire brigade" work and I don't think that is very challenging.

In pig production, we have been evolving for quite a long time because if we only do "fire brigade" work... well, farmers expect a lot more than that! And for us, that is also what's interesting. Pig farming is a batch production, so we have this tendency to always try to do something for the next batch, try to prevent future batches from getting the disease we have now. So having to try this and that is always very dynamic and challenging. So we know that there is always a new batch to come, and that is not the same in cattle farming.

\section{Pig vet, 2014}

Thirdly, pig and poultry vets describe their work as being part of an epidemiological rather than clinical approach to animal health, which they associate with the idea of a preventive rather than curative or therapeutic approach to diseases. This conception is closely linked to the two previous points. On the one hand, it refers to the professional proximity that veterinarians maintain not only with their clients but also with technical advisors, often employees of the co-operative to which the farmer belongs or sometimes of a feed mill company. Indeed, in pig and poultry farming, technical advisors play an important role as they visit the farms much more frequently than vets. Although their role should not involve animal health issues (but rather feeding, housing or husbandry practices), they tend to conceive these aspects as a whole, as do vets when they look at the technical factors (rather than biological and medical ones) of diseases. Animal health is thus the work of a professional trio, whose theoretically distinct roles often overlap, encouraging situations of cooperation and also sometimes conflict (Adam et al. 2017). On the other hand, and consequentially, this so-called epidemiological conception of animal health establishes a form of activity which is not limited to a clinical and individual approach to pathology but which, on the contrary, opens up professional expertise to areas often considered as not specifically veterinary, such as hygiene, nutrition, zootechnics or biosecurity. The knowledge and the toolbox of industrial vets are thus extremely varied and cannot be limited to surgery tools or prescription booklets. 
The veterinarians interviewed often emphasized the "evidence-based" side of their professional expertise (and legitimacy), which is based on the collection and analysis of various data and promotes intellectual stimulations regularly renewed by the diverse situations they must face. They believe all these elements to be part of preventive approaches to animal health and they tend to perceive themselves as health advisers, or "health managers" as Thoms (2015) has shown in the case of German poultry vets.

I graduated from veterinary school in 1985. Then I got a degree in epidemiology. What I realized and particularly interested me during my studies was the difference between individual medicine and herd medicine. So with my education and also my family farming background I realized that individual medicine was more a cost than a profit. So I tried to develop this kind of herd care and preventive approach. I started my professional life in rural medicine in a region that was quite a pioneer in this type of approach, especially regarding reproduction.

\section{Poultry vet, 2015}

We have audit grids and we have exploration tools. For example, I have a device to measure $\mathrm{CO}^{2}$, to dose carbon monoxide. I have a Ph-meter, a conductivity meter, a laser. I have a burette to measure the water flow in the feeding system. I have a light meter in case I need it. I have a camera to explore water pipes. I always have smoke bombs in my car to check ventilation in the buildings. So really, we have exploration tools in the form of scissors and gloves to perform autopsies but also equipment for managing the buildings.

But aren't you stealing work from the technicians?

Technicians do autopsies (laughs)! No, it's true that controlling ventilation doesn't mean that I am able to deal with the farm IT system. So technicians keep their skills. But I consider that it is my job to explain to the farmer that if he has a colibacillosis it's not because a germ fell from the sky but because his ventilation system doesn't work the way it should. That's part of a vet's job, even though it is the technician who is able to fix the problem. We are doing what I might call an etiological or epidemiological diagnosis.

\section{Poultry vet, 2015}

Fourthly, the characteristics of pig and poultry medicine must also be related to the type of animals with which these vets work on a daily basis. Without necessarily following the epistemological principles of the "animal turn" promoted by certain branches of the social sciences (Guillo 2015), which consists in analysing the way in which animals themselves shape human interactions or the socio-technical devices within which they take place (notion of "animal agency"), it must be noted that taking care of chickens or pigs has different implications than is the case with cattle, dogs or cats. Two elements seem central here and are directly related to the characteristics of pigs and poultry and 
the farming systems to which they belong. On the one hand, these animals have a relatively short lifespan: only about 30 days for a conventionally raised chicken (between 90 and 120 days in organic or label farming) and about 6 months for pigs (the sows being slaughtered after 2 or 3 years). It is therefore very different from a dairy cow that must remain healthy and productive for an average of 5 years, or pets that live 10 or 15 years, sometimes more. In these conditions, which obviously also depend on the economic structure of the agri-food industry, animal health becomes part of biological and temporal dynamics where the slightest disorder may have pathological consequences that might be seen as "just-in-time diseases", i.e. health issues directly related to, or shaped by, the sociotechnical and economic infrastructures (including the animal bodies themselves) within which they emerged (Allen and Lavau 2015). On the other hand, the health of chickens and pigs is not considered individually, but rather from a population perspective. These are animals that are reared in batches and it is the group of animals that constitutes the epidemiological reference unit for both the vet and the farmer. In certain cases, particularly in poultry farms where the production cycle is very short, many decisions are therefore made not for the current batch but for the following one, in order to avoid repetition of the same problem.

Overall, all of these aspects are typical of industrial veterinary medicine and, therefore, of this form of expertise and professional legitimacy that can be qualified as preventive veterinary medicine. To sum up, and without prejudging whether or not these elements can be found in other segments of the veterinary profession, we can say that poultry and pig medicine is characterized by (i) a vocation; (ii) a technical and preventive approach; (iii) tripartite work; (iv) animals and farming systems that "call for", or co-construct, this form of expertise.

However, when listening to veterinarians talk about their profession, this way of working on industrial farms does not seem to be linked to the rebuilding claimed by the profession since its incrimination in the AMR problem, even though certain policy measures recently implemented may encourage the development of this preventive and evidence-based approach, such as the obligation to perform antimicrobial susceptibility tests before prescribing critically important antimicrobials (Bourély et al. 2018). Indeed, the roots of this particular form of veterinary expertise can be traced back to the mid-1970s/early 1980s, when some pioneers began to specialize in pig and poultry farms - at that time during a massive industrialization and intensification process.

\section{The origins of preventive approaches in "industrial" veterinary medicine}

During the 1960s and 1970s in France, particularly in Brittany and Pays de Loire, poultry and pig farms expanded rapidly (Nicourt 2013). The mixed crop-livestock model was gradually being replaced by specialist farms which were developing through a twofold process of intensification (increased herd size, confinement and containment of animals, rationalization and (bio)technicization of husbandry methods such as genetics, feeding and pharmaceuticals) and industrialization (concentration and vertical integration of the food chain's stakeholders, and taylorization of farm labour) (Diry 1985). This movement led to the emergence of new needs in terms of health 
management. Firstly, at that time veterinarians knew little about these animals in terms of medical knowledge or techniques (poultry and pig medicine was rarely touched upon in veterinary schools back then). Secondly, the confinement of animals in enclosed buildings led to outbreaks of disease, especially-but not only-infectious diseases which were unknown or at least whose management methods were no longer appropriate. A small number of vets then began to specialize in this type of production, viewing it as a promising and developing market.

Poultry farming was not taught at all. Poultry diseases even less so and the prevention of poultry diseases even less than that. So my gateway to poultry farming was the technical-economic approach to things, and not the purely pathological approach, which I could have done at the time on sheep or cattle. Except that there, I was in a completely capitalist system. As you can see, one can adapt to anything (laughs).

\section{$\underline{\text { Retired poultry vet, } 2018}$}

In the pig sector, it was mainly vets employed by agricultural co-operatives who embarked on the adventure, supported in particular by the creation of the Station de Pathologie Porcine (SPP) (national veterinary laboratory specializing in pig health) in Ploufragan (North Brittany) in 1975 (Fortané 2017). In the poultry sector, which is structured more around industrial groups than around co-operatives, there were more independent vets who were orienting their practices towards this type of clientele. What these veterinarians had in common was the conviction that they could no longer do their job in the traditional way, i.e. as emergency "rural" vets, alone or in partnership in small practices serving a diversified clientele (cattle farmers and pet owners in particular, with a few occasional interventions on poultry or pig farms). Moreover, they were convinced that their job was to accompany the development of intensive and industrial livestock farming by providing services adapted to the specific animal health issues of this sector, and that their own organization had to follow and mimic the development of the industry they were working for. The term "industrial vets" therefore refers not only to the kind of clientele they were (and still are) working for, but also to their own state of mind and conception of veterinary medicine, as a profession and as a business.

In fact, we were the defenders, the propagators of intensive livestock production. We never denied that, that's what we were employed for. We were just saying "ok, but the conditions for success are this and this and this".

$\underline{\text { Retired pig vet, } 2014}$

At the time, there was a double-digit growth in the sector, so we said: "we must stick to the development of this sector". We were focused on poultry, we had almost given up on pigs. We said: "We have to stick to the leaders". Very quickly, in 84-85, we said: "it's X [one of the biggest poultry industrial group], we'll stick 
to $X$, we'll stick to the growth of $X$, like a leech, we'll never let it go". That was our aim in 84-85 and it became concrete a little later when we were working for $X$, even though we weren't their official vets. (...) We had developed well in 84-85, so how could we consolidate our system, how could we really sell it, how could we duplicate it? This is where the notion of "global offer" began. Here, you find three activities: the veterinary practice, including advice and training, the medicines and the analysis. When you come here, you have this "global offer": the lab part, the drug part and the advisory part.

\section{Retired poultry vet, 2018}

The way this pioneering generation of pig and poultry vets worked was characterized by their capacity and interest in conceptual innovation and do-it-yourself techniques for responding to the often unknown situations they had to face. On the one hand, it concerned the development of pharmaceutical products adapted to these animals and their husbandry conditions, at a time when the pharmaceutical industry was producing very few medicines for this type of livestock, not considering it to be a worthwhile market. It was therefore not uncommon for veterinarians to order pharmaceutical raw materials (rather than manufactured drugs) in order to themselves prepare a product that could be effective in terms of both pharmacological (e.g. combining an antibiotic and an anti-inflammatory) and galenic properties (e.g. designing a drug in the form of a powder to be spread in bedding rather than to be mixed with food-for dermatological infections in particular).

In 83-84, we had outbreaks of staphylococci. Obviously, the animals caught it very early because they already started to have small pimples at 8-10 days. So the mother was a carrier, so we thought: "what if we use an antiseptic powder?" Then we thought: "we need a powder that is very powdery, that adheres well to the skin". We worked on the galenic, excipients and everything. We developed a powder and tried it and the farmers said: "this works well".

Who were you doing this with?

We made the powder ourselves. We had a mixer. In our pharmacy, we had a manufacturing workshop. (...) It was common at the time. We had the right to make extemporaneous preparations that were the result of our prescription and our imagination.

\section{$\underline{\text { Retired pig vet, } 2018}$}

On the other hand, this broader conception of the veterinary role could be seen in the holistic vision of health that these professionals were promoting. Most of the time, they combined therapeutic intervention with bacteriological analysis and research on animal nutrition (some of these vets were also employed by feed mills). All of the larger practices of this pioneering generation developed a laboratory, sometimes a makeshift one, in order to perform the autopsies necessary for bacteriological tests. 
$X$ [a pioneering poultry vet] had a very solid clientele of horses and cattle at the time, but he was interested in birds. (...) When the first industrial poultry farms, the large flocks of 300 to 400 chickens, settled in, he moved towards that. Very quickly, he realized that the bigger the batches of poultry became, the more the diagnosis had to go through the laboratory in order to be accurate - at least regarding bacteriology and parasitology. Since he's a guy who doesn't want to do things by half, he thought: "I can't make a laboratory like that, we suck as vets, I need training". He said to his partner: "I will go to Pasteur". ${ }^{11}$ Further education at that time was unimaginable. (...) Then, when he came back, he started his own lab and that was really the beginning of the adventure.

\section{$\underline{\text { Retired poultry vet, } 2018}$}

In the pig sector, it is interesting to note the extent to which the history of the Ploufragan station is still rooted in the North Brittany territory, as many generations of veterinarians, still today, have done part of their training there or continue to rely on the expertise of SPP's epidemiologists or microbiologists in their daily activity (especially in the case of outbreaks of infectious diseases or to set up clinical trials).

Oh yes, with regard to emerging diseases, I often contacted the station when we saw pathologies that seemed new to us. This was the case for many diseases. There was streptococcal, there was respiratory coronavirus. At the SPP, I called [the vet in charge] and the others, they were not convinced because at that time there was still pseudorabies in the farms. I had to talk to [a pharmaceutical company] about it and then the SPP became interested.

\section{Retired pig vet, 2014}

Indeed, veterinary researchers from the SPP had developed a preventive approach to animal health called "ecopathology" that had considerable success among pig vets and farmers in the 1980s (Fortané 2017). It was mostly based on an epidemiological conception of animal health (disease outbreaks are related to multiple variables, particularly "technical", i.e. non-clinical ones), and was adapted to the specific issues and husbandry conditions of intensive livestock farming. In this regard, the type of preventive veterinary medicine which was developed at that time in France would seem to have similar characteristics to that which had flourished in the UK slightly earlier (from the 1950s to 1970s) (Woods 2013): animal health has to be conceived at the scale of the herd (and not the individual animal), be articulated to non-medical matters such as feeding, housing and genetics, and integrate the economic issues of performance and profitability within the advisory support vets provide to their clients. The most important difference during the process of institutionalizing these preventive approaches in France and UK seems to be the role played by public authorities. While in the UK, the State firmly supported the development of preventive veterinary medicine as a way to accompany the modernization of British livestock farming, in France, except for the SPP which was partially founded by

\footnotetext{
${ }^{11}$ The Pasteur Institute in Paris provides veterinary and medical practitioners with training in microbiology and epidemiology.
} 
local authorities and State veterinary services, most of the preventive approaches that flourished in the 1980s were supported by the private engagement of pioneering vets trying to respond to the challenges of a growing industry and, in the meantime, to capture the market of "industrial" veterinary services. ${ }^{12}$

All in all, the point here is not to say that contemporary pig and poultry vets are nowadays using the exact same techniques and knowledge of the preventive approaches developed in the 1970s and 1980s, or even to suggest that all industrial vets of that time were doing exactly the same. ${ }^{13}$ It is rather to demonstrate that this type of veterinary medicine has at least a 30 to 40-year history in these sectors and that some aspects of this can still be seen in the way that modern industrial vets continue to work (and to perceive their job and professional identity), such as the importance of technical expertise, epidemiological knowledge and bacterial laboratory - in other words, that a diversified form of veterinary expertise is required. Even though this history has more or less vanished from the profession's official memory, a few unconscious vestiges of it can still be seen in recent AMR debates. For example, during the campaign promoting the AMR policy in the pig sector in 2014, an implicit link was made between this pioneering medicine and the kind of expertise which is now considered to be the future of the profession and through which veterinarians tend to legitimize their role as the guardians of antibiotics. This is demonstrated by the utilization of the ecopathology icon which expresses the holistic conception of animal health (namely the so-called "Ploufragan hexagon") to promote good veterinary practices in antimicrobial use in livestock (Fig. 2).

All these elements show that what is now called preventive veterinary medicine and which is perceived, within the political context of the AMR problem, to be the model of professional expertise towards which veterinarians must turn, is not fundamentally new, at least within the knowledge and practices of pig and poultry vets. But what about the economic model on which this kind of expertise is based and how it is actually related to the use of antimicrobials?

\section{The economic structures of professional expertise}

Although it is in fine difficult to associate the development of preventive approaches with the reaction of veterinarians to their incrimination on the AMR issue, contrary to what the sole examination of professional discourses in the press or in various

\footnotetext{
${ }^{12}$ It should also be noted that in the UK the development of preventive approaches concerned farm animal medicine in general (so mostly cattle medicine), while in France this movement was located in "industrial" pig and poultry medicine - although due to local history it would seem that in some regions other forms of preventive medicine were also developed in a small number of cattle veterinary practices as from the late 1970's (Combettes et al. 2012).

13 This is indeed the purpose of talking about "preventive approaches" in the plural, i.e. to highlight the fact that these approaches could be rooted in different local histories or individual trajectories yet still share some common principles. While pig vets were mainly referring to ecopathology by virtue of their link with the SPP, poultry vets did not use a specific term (preventive, holistic or epidemiological approach, global offer, etc.). Nevertheless all industrial vets were (and still are) referring to what they were (are) doing with the same kind of contrasting schemes: epidemiological vs clinical, preventive vs curative, herd vs individual, technical vs medical, etc. which I consider to be the common ground of "preventive approaches to animal health" with, in addition (cf. next section), an economic model based on free-of-charge services funded by drug sales and aimed at "capturing" clients.
} 


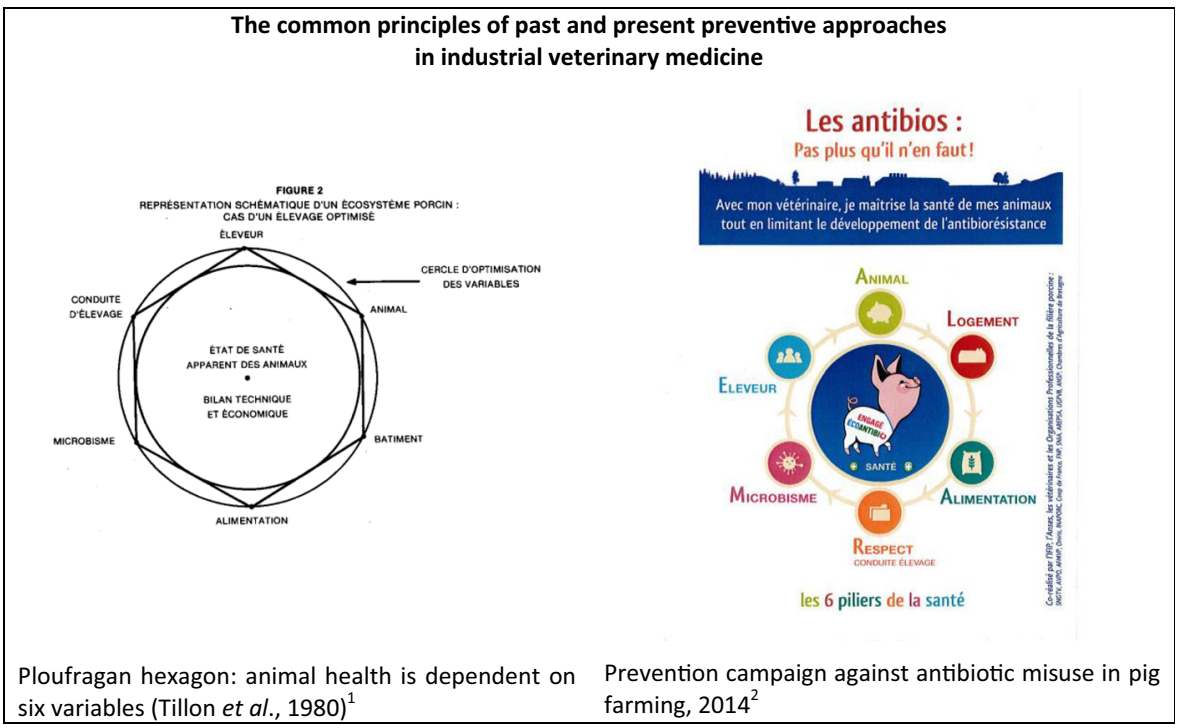

Fig. 2 The common principles of past and present preventive approaches in industrial veterinary medicine. 1- Ploufragan hexagon: animal health is dependent on six variables (Tillon 1980). This famous diagram represents the way animal health (and economic performance of the farm) is conceived within the ecopathological framework: it is correlated to six variables, namely the farmer, the animal, housing, feeding, microbes and husbandry practices. At that time, it was considered quite innovative to claim that veterinary expertise should take into consideration all these aspects and not just focusing on animals and microbes (Fortané 2017). 2- Prevention campaign against antibiotic misuse in pig farming, 2014. This poster used in the AMR campaign perfectly reproduces the six "ecopathological" variables (here referred to as the six "pillars" of animal health). It says: "No more antibiotics than needed. With my vet, I manage the health of my animals while limiting the use of antibiotics". This poster therefore illustrates how preventive approaches within veterinary medicine are deemed to be a solution to reduce antimicrobial use

institutional spaces relating to AMR policy-making might suggest, nowadays this model has nevertheless become more visible and contributes to the re-legitimation of the veterinary profession (Badau et al. forthcoming). However, the idea that preventive approaches will make it possible to move away from the economic model placing antibiotic sales at the heart of veterinary income seems more dubious, as the development of said preventive approaches was in fact based on this very system.

\section{The construction of a captive market}

By the notion of economic model, we mean the way in which veterinary services are monetized. One of the key elements of the criticism against veterinarians with regard to the AMR issue has been the fact that their sources of income are largely dependent on drug sales (antibiotics in particular). However, whereas professional discourses seek to explain that the development of a preventive medicine in which antibiotics no longer hold a central place will make it possible to change the "business model" of veterinary practices, it is on the contrary clear that this economic model based on drugs sales has in fact allowed these preventive approaches to flourish. Even though it is difficult to concretely assess the accountability of veterinary practices due to a lack of available data (in particular if we wish to distinguish between different segments of the 
profession), we can nevertheless rely on estimates from various literatures. A 1984 veterinary thesis on the structure of the drug market considered that drug sales were generating 30 to $40 \%$ of the income of farm animal practices (Rivière 1984). Thirty years later, in the midst of the AMR debates, a report by the French Food, Agriculture and Rural Areas Council estimated this figure to be around $60 \%$ for farm animal vets in general, and up to $80 \%$ (including a high proportion of antibiotics) for industrial vets (Dahan et al. 2013, p. 20). So one cannot help but wonder what happened during the three last decades and to what extent this evolution of the economic model of veterinary activity has in fact supported the development of preventive approaches to animal health, contrary to the prospective narrative the profession has constructed to defend its role as the guardian of responsible use of antibiotics.

The answer is actually quite simple, and is a classic case in agricultural economics: the sale of inputs funds the advice. In the case of industrial vets, the context in the 1980s and 1990s favoured the emergence of strong competition between practices seeking to capture the growing clientele of pig and poultry farmers. This competition was also heightened by the fact that the supply of veterinary goods and services was still highly heterogeneous, due to the non-existence of standardized pharmaceutical, hygienic or nutritional products adapted to the new health problems caused by the intensification of animal husbandry. Consequently, pharmaceuticals, which are the only product on which veterinarians have a monopoly for prescribing (and therefore advice) and dispensing (and therefore sales), became the main means of ensuring client loyalty. Since the 1975 Act, the veterinary drug market has thus been developing into a captive market, where drug sales have gradually become the only monetized exchange between vets and farmers, funding all the services actually offered by veterinarians (visits, diagnosis, analyses, prescription, audit, etc.) (Bonnaud and Fortané 2018). Indeed, preventive veterinary medicine developed on the basis of this economic model which corresponded, on the one hand, to that of the few pioneering independent practices which owned bacteriology laboratories, small drug manufacturing factories or wholesale companies and, on the other hand, to that of the agricultural co-operatives which the 1975 Act established as lawful drug suppliers and which, until 2007, employed veterinary practitioners in this regard. Indeed, it was precisely by providing a whole range of "free of charge" services (visits, advice, vaccination, etc.) that these vets were able to disqualify their competitors, i.e. their "emergency" or "fire brigade" colleagues who offered little advice but were able to monetize their occasional interventions.

Yet were the farmers prepared to pay for their visits, as they would have done with rural vets at the time? Because, even the independent vets specializing in group pathologies, so pig and poultry, like those from $X$ [one of the pioneering veterinary practices in industrial medicine], most of the time, they did not charge for their visit, their visit was paid through drug sales. In fact, most farmers were smart enough to understand that if they were satisfied with the services of a vet or a veterinary practice, they should buy drugs to pay them indirectly, even if there were price differences. I think it was like this: "You do me a favour, I need you, you treat, you prevent, we work together, I buy drugs". It was indirect payment. (...)

I've always thought that the best way to ensure farmers' loyalty is to be efficient. Then they will not even talk about drug prices. There was a time when vets were 
very active on the farms. If farmers were happy with our services, [they didn't care about] the price of the drugs. At one point, we were a little cheaper but we weren't always cheaper. We were also known for being reasonably priced, so that there wasn't too much competition. Sure, we weren't the cheapest on the market, but that's not the issue. But I'm convinced, and I know that's the way it was for a lot of people, the best way to keep them was to meet their expectations. Their expectations were simple: "I have problems, I have to solve them, help me solve them, if it takes time ok it takes time". It was up to us to meet farmers' expectations in terms of health. If the farmer was satisfied, the rest would follow, he would take the feed, the genetics, the drugs. We had an indirect commercial role, but we could only do it if we were efficient. (...)

But some of them stopped buying our drugs. They told me: "You're too expensive". So I answered: "If we are too expensive, you go elsewhere, but you no longer have the services". What does he want? A cheap price, but with a service that will be what it will be, it may be very good, ok, but the farmer is free to choose. However, he fully understood that he could not ask us to come ten times a year or twenty times and then buy zero medicines. Moreover, I tell most people: "we provide you with important services, we know that you also like to work with other people from time to time, at X for example, so don't buy everything from us, but buy a little from us, as we come to see you regularly and we need a return". And then everything was fine, they bought some elsewhere and some from us.

\section{Retired pig vet, 2014.}

The construction of a captive market is therefore a central dimension of what I call here "the economic structures of professional expertise". The development of preventive approaches within industrial veterinary medicine is not only the result of the emergence of new demands or needs from farmers, but it is also and above all the consequence of the intra- and extra-professional competition that veterinarians have had to face after the 1975 Act. Prescribing and dispensing pharmaceuticals, combined with a holistic expertise, is a means of capturing a clientele through a simple and exclusive form of economic contracting (the sale of drugs) while providing a wide range of services (diagnosis, advice, etc.). It is indeed the articulation of these two dimensions that makes it possible to prevent, or at least reduce the risk, that clients are captured by a competitor. In this sense, preventive approaches to animal health must be read simultaneously as a professional and a business model, these two dimensions being constitutive of each other. Such economic structures of veterinary expertise have been observed in another context, that of the USA in the 1950s and 1960s. Smith-Howard (2017) shows how American veterinarians, who did not have a monopoly on the sale of medicines, gradually established themselves as the main distribution channel by coupling their prescriptions with preventive services that provided real added value to farmers, compared with pharmacists or other retailers who were merely supplying the drugs. A linguistic distinction has even emerged between "dispensing" and "merchandising", contributing to (re)establishing the legitimacy of veterinarians on a new basis. In the end, it is therefore in the light of this link between professional expertise (in the sense of type of knowledge and services) and business model (in the sense of how these services are economically valorized) that we must question the current context and controversies surrounding AMR. 


\section{Towards new business models for veterinary practices?}

It seems finally a little too simplistic to support the thesis of the professional conflict of interest that human health actors have mobilized to point out veterinarians' responsibility in the AMR problem, because of their dual monopoly on the prescription and supply of medicines. In fact, the structure of the veterinary drug market has set up the sale of pharmaceuticals as a quasi-unique way of making professional expertise profitable, even though this expertise was already based on preventive approaches (and thus diversified services) for quite a long time. The current challenge for the veterinary profession is therefore less the development of a preventive medicine than the renewal of the economic model on which it has been based until now. In this regard, it is actually interesting to note that the vets I met in this study clearly mention this issue and have already started to develop strategies to deal with it.

That's exactly the issue we now have with my colleague. I'm right thinking this. Historically in poultry, no charge is really made for visits. Overall, payment is made through [the purchase of] medicines, which is, for me, not a bad thing if it is not excessive. At some point, when we take the example of human medicine, you pay a doctor, you pay a pharmacist, everyone is happy because there is healthcare security. The day there's no healthcare security, I don't know what we're going to do. So that's what I explain to farmers: "The day you have to pay a vet and a pharmacist it's going to cost double". So at the moment, with this system, you only have one cost, so in theory that's good. Indeed, there can be misuse, someone who would systematically prescribe medicines even if there is no need. This is clearly an issue and it is difficult to explain, that's our problem. But honestly, every morning when I stand up, I don't say to myself: "I will prescribe 10 kilos there, 15 kilos there and 5 kilos there, and the day is done". That's absolutely not the way I think, but I can understand... and I understand when people are telling me: "Yes, but if you sell, you earn". That's all there is to say. It's been on my mind for a year.

\section{$\underline{\text { Poultry vet, } 2015}$}

Firstly, particularly in a context where profits on medicines are now more strictly controlled (and therefore more limited), it seems essential for the veterinary profession to be able to charge for services that were previously funded by drug sales. This is the case in particular for visits, technical advice and bacteriological analyses (the latter were generally charged but often below the real cost-which could be high for the veterinary practice that has to employ laboratory technicians).

Secondly, there are strategies consisting in investing in hygiene and/or nutrition product factories (in particular disinfectants and food additives), in order to be able to sell products other than just pharmaceuticals. It is a strategy of diversification of the professional and economic activity that pioneering independent practices or certain cooperatives employing veterinarians have been using for many years, but which is now tending to become generalized among industrial vets due to the development of franchised practices. 
Company $X$ is a part of group $Y$ [a pig co-operative]. [We sell] zero drugs. There is hygiene, so disinfectants and detergents, and also nutrition and probiotics, i.e. products that can be added to food or that farmers can put in drinking water. You have suppliers for these products or you manufacture them yourselves?

There are products that we make ourselves, otherwise we choose products from everything we know, and from people we work with. We are doing clinical and zootechnical trials as well. We've written some articles, I did one on swine haemorrhagic dysentery. We did an international article in which we showed that we can prevent it with a certain probiotic. It allowed me to go and see farms in Portugal, Spain and England as well. I even went to Cuba for X.

Trying to sell products?

To preach the good word! We hold meetings on a given theme, for example it might be digestive issues, and we talk about the ecopathological approach. Rather than using this or that antibiotic, there are other things that work, and we know this because we have experience with farmers from Y. Thanks to this experience, and because there were disastrous situations where antibiotics no longer worked, we can tell other veterinary colleagues [that these products work well].

\section{$\underline{\text { Pig vet, } 2014}$}

A third strategy consists in developing various forms of contractualization with the clients. For example, the vet interviewed below tries to imagine an annual flat-rate model that would cover all veterinary services, from advice to medicines. This would be based on a form of insurance, where some farmers would ultimately pay a higher price than the actual cost of the services they have received, while others, particularly those facing more health issues, would pay a lower price (although the reverse might be true from one year to the next). In fact, this system is similar to the one set up by the so-called "veterinary groups under contract" in central and south-eastern France, but which was only developed in areas where livestock farming is not widespread i.e. in small and medium-sized cattle or sheep farms connected to local markets; this system is mainly associated with alternative agricultural projects resulting from 1970 s protest movements (Combettes et al. 2012). It would be interesting to know the extent to which such a model might be easily generalizable in the heart of an industrialized agri-food system where farmers are involved in more complex and constraining chains of interdependence with upstream and downstream industries. This trend resonates with certain dynamics currently observable in the UK where farm animal vets are also concerned about the sustainability of their economic model and are trying to develop similar forms of contractual veterinary services, although less than $10 \%$ of the clientele of the practices trying to develop these kinds of contractual schemes have adopted it so far (Ruston et al. 2016). The economic model and the type of goods and services that veterinarians can provide are nevertheless now considered to be key criteria for the sustainability of veterinary businesses (Henry et al. 2016). 
So I've been thinking for a year. Now I'm going to test a new system, a comprehensive flat-rate package. I'm testing it, it's brand new, with two or three farmers. This is a complete veterinary follow-up, which includes visits and medicines. We don't talk about fees anymore. [...] So I don't know yet. My package system might be good in theory, maybe not good if farmers... Because you know, on the farms, there are major variations in antimicrobial consumption. At some point the package is going to be an average. Some of the farmers will find my services a little bit too expensive whereas others will like it, but yes perhaps major antibiotic users so it might be a bad influence for them. I'm not claiming victory yet, but I'm trying to find another system.

\section{$\underline{\text { Poultry vet, } 2015}$}

A fourth strategy consists in monetizing certain veterinary services no longer to farmers, but to co-operatives. This relates to at least two types of activity. First of all, it concerns the follow-up of "herd health plans" that co-operatives are obliged to set up if they want to be approved for selling veterinary medicines, in accordance with the 1975 Act. It is of course an activity that has existed for a long time, but that many cooperatives delegated to their employed vets until 2007 . The second activity relating to this strategy is linked with the development of new roles for veterinarians, in particular those of standards controllers or certifiers. Indeed, with the development of "antibioticfree" labels, more and more co-operatives are asking vets to help them implement such standards. For example, vets have to perform "pharmaceutical audits" in an attempt to recruit farmers who can comply with such specifications, or to set up protocols to monitor antibiotic use and help farmers reduce it.

When the co-op announced its project [antibiotic-free pigs], some farmers called me the day after, or I called them, to be part of this project. So for those who were still using antibiotics in feed there were still some stages to go through but when a farmer calls you, you think that you're going to need him for the project so you have to find alternatives. You have to know if he really needs antibiotics and how to reduce them. So this is where you have to set up a procedure, to find ways to identify the flaws... and in the end this is the perfect way to familiarize farmers with this issue. (...) Well the farmer has to be motivated but this is where the bill of specifications helps, because there is an added-value. And there is also glory and self-satisfaction because the added-value isn't much, but there is both.

\section{Pig vet, 2014}

Yet these new roles for veterinarians, or more exactly these new ways of monetizing their expertise, are associated with a redefinition of their professional identity that vets are not always comfortable with. While being a health advisor rather than a clinician is perfectly in line with their preventive conception of veterinary medicine, becoming a sort of controller and sometimes even a sales representative in charge of enrolling and accompanying farmers in quality insurance schemes is not necessarily easy. This difficulty has also been noted among UK cattle vets who felt conflicted between their role of practitioner (within the framework of their relationship with their clients) and 
their role of "enforcers" of biosecurity practices (while implementing policy measures to prevent bovine tuberculosis), although in this case they were acting on behalf of the government and not for market schemes of private stakeholders (Enticott 2012). The vet interviewed below explains the practical and ethical adjustments he has had to make to accommodate this new way of valuing his professional expertise, and the limits he personally sets to remain in what he considers to be the role of a health advisor.

So luckily we have some experience [with following up on bills of specifications], especially with welfare standards. In this standard, the farmers have to use the co-op's animal feed. So our experience allows us to recognize the feed bags. And one day I was on a farm visit, and I saw a feed bag. And I thought "but this is not the feed from the co-op?". Because I know that it is normally small granules, and this time it was big granules. So here, clearly, the farmer is not complying with the bill of specifications! So you see, if you look carefully, you can see things. Well you can't see everything, especially when farmers don't want you to know... because in this case he even didn't think about it. Leaving the bag like that... it is sure that he's going to be in trouble with the co-op. But you won't see the ones who really want to cheat!

And in this example, what happened in the end? You just let him know, asked him to be careful, and let it go? Or might you impose sanctions at some point?

Well that's not for me to decide. But the question for me is whether or not I want to report someone. One day the co-op boss asked me [about the co-op's granules] but I replied that I didn't have time to check whether every farmer in the quality insurance scheme actually uses its granules. (...) But no, what I do, mostly, is warn the farmer. I tell him that he has been found out. And I tell him that the coop is fairly meticulous and that if they find out they will take him off the scheme. So for a few months he will lose 23 cents and he won't be happy. So that's the situation. And they are absolutely capable of doing it, without any doubt. So this is what I do, I warn him but I don't think it is my role to report him, or to impose sanctions.

$\underline{\text { Pig vet, } 2014}$

\section{Conclusion}

"If I change, I may lose my clients. But if I don't change, I might lose my job"

$\underline{\text { Poultry vet, } 2015}$

By cross-examining the development of the drug market and the professional expertise of French "industrial" vets, this article has aimed to articulate reflections from the sociology of professions and the anthropology of medicines. The AMR problem is a very interesting case-study through which to make such an articulation 
fruitful. Indeed, numerous works of research in the anthropology of medicines invite us to analyse drug use through the lens of the global circulation of pharmaceuticals and not just by focusing on the practices and knowledge of end-users, be they farmers or patients (Whyte et al. 2002; Petersen 2014). Antibiotic use cannot therefore be disconnected from upstream practices (or pharmaceutical "life stages", as anthropologists of medicines would call them) such as production, distribution, prescription and sale. Though little is yet known about the structure of the veterinary drug market, we have shown that as key actors at the heart of the veterinary drug chain, involved in many areas of this global circulation of pharmaceuticals, veterinarians play a major role in the regulation of antibiotic use - particularly industrial vets who are not only involved in prescription and delivery but also in some cases in production and distribution. This result is therefore interesting from the point of view of the sociology of professions as it shows that the "jurisdiction" (Abbott 1988, 2005) of veterinarians is certainly more complex than them being mere practitioners of animal healthcare. Indeed, when we look at the veterinary profession as a whole it becomes quite obvious that veterinary knowledge is involved in many domains of animal health and food safety, from farm to policy and industry (Bonnaud and Fortané 2016, 2018). What this article shows, in addition to describing the specificities of a relatively unknown segment of the profession, is that this highly diversified form of professional expertise, and therefore the variety of areas in which it can be exerted, can also be concentrated within a tiny group of professionals, namely pig and poultry vets. Moreover, even though it still has to be more broadly demonstrated, it would seem that the trajectory of this particular segment, characterized by the development of specific approaches and economic models, is somehow quite representative and/or influential of more global changes that are now affecting the profession as a whole (at least in farm animal medicine). The expansion of the activity of industrial vets within the drug chain and the "technical" domains of livestock farming indeed corresponds to a (conflicted) evolution of veterinary jurisdictions that echoes the profession's ongoing attempts to renew itself in the context of AMR controversies. All in all, articulating reflections from the sociology of professions and the anthropology of medicines has allowed us to highlight the "economic structures of professional expertise" (that is to say that professional practices and knowledge are shaped by the way they are economically valued on a given market), which is of considerable importance for the analysis of the AMR problem.

Indeed, it underlines the fact that AMR cannot be addressed by simply focusing on antibiotic use or prescription and, more importantly, it shows that the framing of the AMR problem cannot be understood without reconnecting it with the global transformations of the veterinary profession (both in terms of expertise and business model). In this regard, we have shown that the veterinary profession has developed a prospective narrative to defend its role as the guardian of antibiotics (i.e. moving towards preventive approaches in order to prescribe less antibiotics and be less dependent on drug sales) that does not fully correspond to either the history or the actual practices of industrial vets. Such approaches have in fact already existed for many years and it is thanks to this diversified veterinary expertise that this segment of the profession has developed. However, the economic model upon which this expertise has been based is in fact the one which is nowadays criticized within AMR controversies (i.e. the sustainability of veterinary businesses being highly dependent on antibiotic sales), so that it would appear relatively doubtful, if not ironic, that the profession now brandishes 
preventive approaches as the undisputable solution to antibiotic overuse or misuse. Indeed, drug sales were almost the only way of monetizing veterinary services in the pig and poultry farming sectors and this is how the pioneering generation of industrial vets disqualified their traditional competitors, by "enrolling" clients through the development of a captive drug market. So although promoting preventive approaches is probably the right way to encourage veterinarians to move towards a "health advisor" role where antibiotics are neither the main tool of their activity nor the main source of their income, the profession still has to develop economic models (practice accountability, contractual arrangements with the clients, etc.) that do not rely on drug sales. Recent policy measures and incentives are probably pushing in this direction, as are broader trends such as the development of franchised practices and new professional roles and status, but this still has to be empirically confirmed (even though we know that over recent years antibiotic use has already started to decrease). Social sciences have a major role to play here, by being theoretically and methodologically innovative in order to grasp complex and entangled dynamics to which the AMR problem has just begun to draw attention.

\section{Compliance with ethical standards}

Conflict of interest The author declares no competing interests.

\section{References}

Abbott, A. (1988). The system of professions: an essay of the division of expert labor. Chicago: The University of Chicago Press.

Abbott, A. (2005). Linked ecologies: States and universities as environments for professions. Social Theory, 23(3), 246-274.

Adam C. et al. (2017), Autonomy under contract: the case of traditional free-range poultry farmers. Review on Agricultural, Food and Environmental Studies, 98(1-2), 55-74.

Allen, J., \& Lavau, S. (2015). Just-in-time' disease: biosecurity, poultry, and power. Journal of Cultural Economy, 8(3), 342-360.

Badau, E. (2016). L'antibiorésistance à l'épreuve des discours de la presse Agricole. Questions de communication, 29(1), 67-85.

Badau, E., et al. (forthcoming), Les appropriations de l'antibiorésistance en France : la carrière d'un problème public au sein de la presse vétérinaire (2006-2014), in S. Bernardin (ed.), Croisades privées et problèmes publics. L'héritage sociologique de Joseph Gusfield, Rennes. Presses Universitaires de Rennes.

Berdah, D. (2012). Entre scientifisation et travail de frontières : les transformations des savoirs vétérinaires en France, XVIIIe-XIXe siècles. Revue d'histoire moderne et contemporaine, 59(4), 51-96.

Berdah D. (2018), Abattre ou vacciner : La France et le Royaume-Uni en lutte contre la tuberculose et la fièvre aphteuse (1900-1960), Paris, Editions de l'EHESS.

Bud, R. (2007). Penicillin: triumph and tragedy. Oxford: Oxford University Press.

Bonnaud, L., \& Fortané, N. (2016). Au-delà des crises de santé animale. Pour une sociologie de l'action publique vétérinaire. Gouvernement et action publique, 5(3), 131-140.

Bonnaud, L., \& Fortané, N. (2018). L’État sanitaire de la profession vétérinaire. Action publique et régulation de l'activité professionnelle. Sociologies, 9(3), 253-342.

Bourély, C., et al. (2018). Why do veterinarians ask for antimicrobial susceptibility testing? A qualitative study exploring determinants and evaluating the impact of antibiotic reduction policy. Preventive Veterinary Medicine, 159(1), 123-134.

Combettes, P., et al. (2012). La santé animale sociale et solidaire. Le sociographe, 5, 261-284.

Corley, T., \& Goldey, A. (2011). The veterinary medicine industry in Britain in the twentieth century. Economic History Review, 64(3), 832-854. 
Coyne, L., et al. (2016). Understanding the culture of antimicrobial prescribing in agriculture: a qualitative study of UK pig veterinary surgeons. Journal of Antimicrobial Chemotherapy, 71, 3300-3312.

Dahan M. et al. (2013), Encadrement des pratiques commerciales pouvant influencer la prescription des antibiotiques vétérinaires, Paris, IGF/ IGAS/CGAAER.

Diry, J.-P. (1985). L'industrialisation de l'élevage. Économie et géographie des filières avicoles et porcines. Paris: Editions Ophrys.

Enticott, G., et al. (2011). The changing role of veterinary expertise in the food chain. Philosophical Transactions of the Royal Society B, 366(1573), 1955-1965.

Enticott, G. (2012). The local universality of veterinary expertise \& the geography of animal disease. Transactions of the Institute of British Geographers, 37(1), 75-88.

Fortané, N. (2016). Le problème de l'antibiorésistance en élevage : essai de généalogie et caractérisation. Questions de communication, 29(1), 49-66.

Fortané, N. (2017). Naissance et déclin de l'écopathologie (années 1970 - années 1990). L'essor contrarié d'une médecine vétérinaire alternative. Regards sociologiques, 50-51, 133-162.

Fortané N. (2019), Veterinarian 'responsibility': Conflicts of definition and appropriation surrounding the public problem of antimicrobial resistance in France. Palgrave communication, 5, article no. 67.

Gardiner, A. (2014). The 'dangerous' women of animal welfare: How British veterinary medicine went to the dogs. Social History of Medicine, 27(3), 466-487.

Guillemot, P., \& Vandaële, E. (2009). L'arrêt Riaucourt et ses effets. Bulletin de l'académie vétérinaire de France, 162(2), 171-180.

Guillo D. (2015), What is the place of animals in the social sciences? The Limits to the Recent Rehabilitation of Animal Agency, Revue Française de Sociologie, 56, 135-163.

Henry C. et al. (2016), Exploring the sustainability of small rural veterinary Enterprise, Journal of Small Business \& Enterprise Development, 23(1), 259-273.

Hubscher, R. (1999). Les Maîtres des bêtes. Les vétérinaires dans la société française. Paris, Odile Jacob: XVIIII-XXe siècles.

Kahn, L. (2016). One health and the politics of antimicrobial resistance. Baltimore: Johns Hopkins University Press.

Kirchhelle K. (2018), Pharming animals: A global history of antibiotics in food production (1935-2017), Palgrave Communication, 4, article no. 96.

Mitsuba T. (2017), Entangled histories: German veterinary medicine, c.1770-1900, Medical History, 61(1), $25-47$.

Morris, P. (2012). Managing pet owners' guilt and grief in veterinary euthanasia encounters. Journal of Contemporary Ethnography, 41(3), 337-365.

Nicourt, C. (2013). Etre agriculteur aujourd'hui. Paris, Editions Quae: L'individualisation du travail des éleveurs.

Observatoire national démographique de la profession vétérinaire (ONDPV). (2018). Atlas démographique de la profession vétérinaire. Paris: Conseil national de l'ordre des vétérinaires.

Petersen, K. (2014). Speculative markets : Drugs circuits and derivative in Nigeria. Durham, NC and London: Duke University Press.

Piquerez, L. (2019). Une frontière géographique, des frontières de compétences: le cas de l'antibiorésistance en santé animale en France et en Suisse. Vers un dépassement des frontières? Strathèse, 9.

Podolsky S. (2018), The evolving response to antibiotic resistance (1945-2018), Palgrave Communication, 4, article no. 124.

Rivière S. (1984), Achat et vente en gros de médicaments : structures mises en place par la profession vétérinaire, Thèse pour le doctorat vétérinaire, Ecole Nationale Vétérinaire d'Alfort.

Ruston, A., et al. (2016). Challenges facing the farm animal veterinary profession in England: a qualitative study of veterinarians' perceptions and responses. Preventive Veterinary Medicine, 27, 84-93.

Sanders, C. R. (1994). Annoying owners: routine interactions with problematic clients in a general veterinary practice. Qualitative Sociology, 17(2), 159-170.

Shortall O., et al. (2016), Broken biosecurity? Veterinarians' framing of biosecurity on dairy farms in England, Preventive veterinary Medicine, 132, 20-31.

Shortall, O., et al. (2018). True cowmen \& commercial farmers: exploring vets' \& dairy farmers' contrasting views of 'good farming' in relation to biosecurity. Sociologia Ruralis, 58(3), 583-603.

Smith-Howard, K. (2017). Healing animals in an antibiotic age. Veterinary drugs and the professionalism crisis, 1945-1970. Technology and Culture, 58, 722-748.

Speksnijder, D., et al. (2015). Determinants associated with veterinary antimicrobial prescribing in farm animals in the Netherlands: a qualitative study. Zoonoses and Publich Health, 62(1), 39-51. 
Surdez, M. (2009). Les bouleversements de la profession vétérinaire. Lorsque la recherche d'une nouvelle légitimité sociale coïncide avec l'arrivée des femmes, Revue d'études en agriculture et environnement, 90(4), 473-498.

Thoms, U. (2015). Handlanger der Industrie oder berufener Schützer des Tieres? - Der Tierarzt und seine Rolle in der Geflügelproduktion. In G. Hirschfelder, A. Ploeger, J. Rückert-John, \& G. Schönberger (Eds.), Was der Mensch essen darf: Ökonomischer Zwang, ökologisches Gewissen und globale Konflikte (pp. 173-192). Wiesbaden: Springer Fachmedien Wiesbaden.

Tillon, J.-P. (1980). Épidémiologie des maladies du porc liées à l'élevage intensif. Synthèse des travaux réalisés depuis 1977 à partir de la Station de Pathologie Porcine de Ploufragan. Journée de la recherche porcine en France, 361-380.

VetFuturs France. (2018). Le livre bleu : comprendre et anticiper les mutations de la profession vétérinaire. Paris: SNVEL/CNOV.

Whyte, S., et al. (2002). Social lives of medicines. Cambridge: Cambridge University Press.

Woods, A. (2004). A manufactured plague: the history of foot-and-mouth disease in Britain. London: Routledge.

Woods, A. (2011a). The Lowe report and its echoes from history. Veterinary Records, 169, 434-436.

Woods, A. (2011b). A historical synopsis of farm animal disease and public policy in twentieth century Britain. Philosophical Transactions of the Royal Society B, 366, 1943-1954.

Woods, A. (2013). Is prevention better than cure? The rise \& fall of veterinary preventive medicine, c. 19501980. Social History of Medicine, 26(1), 113-131.

Publisher's note Springer Nature remains neutral with regard to jurisdictional claims in published maps and institutional affiliations. 